have been sought on the recommendations, and ministerial decisions are expected at the end of the year. These suggestions might speed up cases and reduce costs a little, but it is hard to see that they will do much to reduce the large problems of not enough people being compensated and awards in medical negligence cases increasing so rapidly.

The defence societies' tinkering consists of pleas to doctors to keep good records (because bad records may make a case indefensible); not to overstep their competence; not to overwork or "lack diligence"; and not to treat patients without seeing or examining them. ${ }^{2}$ This is all good advice but does not attack the root of the problem, unless we assume that that root is incompetence, which most doctors would reject.

To stop tinkering and look for a radical solution, we must look again at what the problem is and what happens now. The main problem is that medical accidents are inevitablein perhaps almost $5 \%$ of cases the Californian data suggest. ${ }^{10}$ Action for Victims of Medical Accidents is right to call in its annual report published last week for doctors to try to do more to prevent accidents and to respond more positively after they have happened, but it must recognise that many accidents are inevitable and that most are not the result of negligence. ${ }^{9}$ After the accident patients may want an explanation, justice, an assurance that it will not happen again to somebody else, or compensation. Action for the Victims of Medical Accidents says that in almost three quarters of cases patients simply want an explanation. ${ }^{6}$ Doctors will also want to do their best to ensure that the accident does not recur, and if they think that it has resulted because of another doctor's illness or incompetence they will want help for the doctor. Yet the present system is not very good at satisfying any of these needs.

Explanation may best be provided by the doctor in charge of the case without any resort to lawyers, advisers, or systems, and the current issue of the fournal of the Medical Defence Union makes it clear that to say sorry is not to admit liability. ${ }^{13}$ If that is inadequate then patients should be able to resort to a complaints procedure that is easily accessible and comprehensible and seen to be fair to both doctor and patient. Better systems are also needed to weed out and help the sick and the incompetent doctor. ${ }^{14}$

And compensation is best provided by a no fault system without resort to law. The best system would be one that compensated all injured people regardless of the cause of their injury-be it disease, accident, or negligence. Such a system almost began in Australia. ${ }^{15}{ }^{16} \mathrm{Next}$ best would be a system such as the New Zealand one that compensated all those injured in accidents, ${ }^{16-20}$ and third best would be a Swedish style system that compensated only those injured in medical accidents. ${ }^{21}$

The moral case for such a system seems unanswerable, but as so often the snag is the money. Doctors should not be beaten by this argument. Firstly, there is some sort of no fault system already in so far as an injured person is entitled to free medical treatment and various social security payments. Secondly, the present system is enormously expensive and, worse, inefficient. The Lord Chancellor's Department estimated that for every $£ 100$ awarded in damages in the High Court the costs were between $£ 50$ and $£ 70,{ }^{4}$ and the National Audit Office published a report a few weeks ago saying that $£ 150 \mathrm{~m}$ is being lost through injured people receiving both compensation and social security payments. ${ }^{22}$ Thirdly, the experience from New Zealand and Sweden shows that these systems are not prohibitively expensive. Fourthly, costing the different systems is very complex and those opposed to no fault systems tend to "rig" the cost in their favour. ${ }^{16}$ And, fifthly, there is a strong moral case for sharing out fairly and efficiently whatever funds we do have-rather than letting them be swallowed up by courts and lawyers and go to one lucky person rather than 50 unlucky ones.

Assistant editor, $B M \mathcal{F}$

RICHARD SMITH

1 Boughton BJ. Medical Defence Union fees. Br Med f 1983;287:364.

Halle HM The cost of medical defence. Foumal of the Medical Defence Union 1986;Summer:3.

3 Royal Commission of Inquiry. Compensation for personal injur in New Zealand. Wellington: New Zealond Goverion of Inquiry.

Lord Chancellor's Department. Civil fustice Review. Personal injuries litigation. London: Lord Chancellor's Department, 1986

Anonymous. Law report. Doctor's inexperience no defence to negligence. The Times 1986 Aug 6:4.

6 Action for the Victims of Medical Accidents. Annual report 1983-4. London: AVMA, 1984

7 Simanowitz A. How large is the problem of medical negligence? Br Med $\mathcal{F}$ 1984;288:1460.

8 Simanowitz A. Negligence claims. Both sides of the coin ... a patient's experience. Fournal of the Medical Defence Union 1986;summer: 14-5.

9 Action for the Victims of Medical Accidents. Annual repont 1984-85. London: AVMA, 1986.

10 Mills DH. Medical insurance feasibility study. West $\mathcal{f}$ Med 1978;128:360-5.

11 Smith R. Malpractice: a New Zealand solution to an American crisis? Br Med f 1985;291:812-4.

12 Dean M. Damages limit plan backed. Guardian 1986 Aug 12:2.

13 Allsopp KM. Saying sorry. Fournal of the Medical Defence Union 1986;summer:2.

13 Allsopp KM. Saying sorry. Fournal of the Medical Defence Union 1986;sum

14 Rhodes P. Incompetence in medical practice. Br Med f 1986;292:1293-4. ational Committee of

Government, 1974. Australio. Wellington: Oxford University Press, 1979.

17 Ison TG. Accident compensation. London: Croom Helm, 1980.

18 Smith R. The world's best system of compensating injury? Br Med f 1982;284:1243-5.

19 Smith R. Problems with a no fault system of accident compensation. Br Med f 1982;284:1323-5.

20 Smith A. Compensation for medical misadventure and drug injury in the New Zealand no fault system. BrMed f 1986;284:1457-9.

21 Oldertz C. The Swedish patient insurance system. Med Leg f 1984;52:43-59.

22 National Audit Office. Recovery of social security benefits when damages in tort are awarded. London: HMSO, 1986.

\section{Neurological manifestations of human immunodeficiency virus infection}

New manifestations of infection with human immunodeficiency virus (HIV) are still being recognised, and the most alarming and recent discovery is that the virus may be neurotropic as well as lymphotropic. It is present in the brains of some (if not all) individuals infected with HIV and can cause neurological disease not only in those with the acquired immune deficiency syndrome (AIDS) but also in those who are immunocompetent and may never develop AIDS as currently defined. Such manifestations need to be distinguished from the various neurological opportunistic infections and tumours that affect patients with AIDS. Further new consequences of infection with HIV are also likely to be noticed in the future.

Early evidence for the presence of the virus in the brain was provided by establishing HIV infection in chimpanzees by inoculating brain tissue obtained at necropsy from patients with AIDS.' Shaw et al showed HIV DNA in the brains of five of 15 patients who died with AIDS encephalopathy using Southern blot analysis and also showed viral specific RNA by in situ hybridisation in four of the five cases. $^{2}$ The virus has been isolated from the brains and cerebrospinal fluid of patients with this condition by using reverse transcriptase activity in cell culture supernatants and confirmed by indirect immunofluorescence. ${ }^{34}$ Synthesis of HIV specific IgG has been shown within the blood brain 
barrier providing further evidence of HIV infection within the central nervous system in patients infected with HIV. ${ }^{56}$

The neurological features of HIV infection may be classified as acute, subacute, and chronic. Three cases of acute encephalopathy, ${ }^{7}$ one of acute meningitis, ${ }^{4}$ and two of acute neuropathy ${ }^{8}$ have been described-all when patients first developed antibodies to HIV. The three patients with acute encephalopathy had fever, general malaise, and changes of mood, and two had epileptiform seizures. But all these recovered almost completely within a week and have had no long term neurological sequelae. Both patients with acute neuropathy had facial palsy, which in one was bilateral and accompanied by sensory and motor impairment of the arms and legs. In each case gradual improvement took place over months.

The most common neurological syndrome has been called subacute encephalitis and occurs in about one third of patients with AIDS..$^{+10}$ This condition is characterised in the early stages by subtle cognitive changes that may progress to serious dementia in several weeks or months. It may appear first as a confusional state together with fever or mild metabolic derangement. The cerebral dysfunction is accompanied by lethargy, loss of libido, and withdrawal that mimic psychological depression and may be difficult to distinguish from mood changes arising as a reaction to illness. Eventually patients may become bedridden and incontinent. Motor signs including generalised hyper-reflexia and increased tone may be seen, and an electroencephalogram commonly shows diffuse bilateral slowing. ${ }^{11}$ Examination of the cerebrospinal fluid often shows a mild pleocytosis and a rise in protein concentration, a lowered glucose concentration, or both. Computed tomography usually shows dilated ventricles and prominent cortical sulci indicative of cerebral atrophy. Histopathological findings in advanced cases include ill defined pallor, multifocal perivascular rarefaction, and focal vacuolation of the white matter along with perivascular and parenchymal collections of macrophages and multinucleated giant cells. ${ }^{10} \mathrm{~A}$ few affected individuals have disseminated cytomegalovirus infection of the brain. In the remaining cases no opportunistic infection is found to account for the changes, and the causative agent is believed to be HIV.

HIV has also been implicated as the cause of three mainly chronic or subacute neurological conditions-vacuolar myelopathy, peripheral neuropathy, and atypical aseptic meningitis. Vacuolar myelopathy was reported in 20 of 89 consecutive patients with AIDS on whom necropsies were performed..$^{12}$ Patients with this condition may complain of motor or sensory symptoms, or both. They may have bilateral or, less commonly, unilateral weakness of the legs, which may coincide with paraesthesiae. Seriously affected patients often have ataxia and incontinence. The peripheral neuropathy seen in patients with AIDs is a symmetrical sensorimotor neuropathy with painful dysaesthesiae and less commonly with weakness and distal atrophy. ${ }^{13}$ It sometimes occurs before AIDS develops, but mononeuritis multiplex appears to be more common at this stage. Finally, an atypical aseptic meningitis may occur in people infected with HIV before AIDS develops. ${ }^{13}$ They present with headache, fever, and meningeal signs but often also have atypical features such as recurrence, chronicity, cranial nerve involvement, and long tract signs. The fifth, seventh, and eighth cranial nerves are the most commonly affected. HIV has been isolated from the spinal cord, cerebrospinal fluid, and sural nerve of patients with AIDS suffering from these conditions. ${ }^{+}$Ho et al have also isolated the virus from the cerebrospinal fluid of two patients with chronic meningitis who had AIDS related complex rather than AIDS and from the cerebrospinal fluid of a previously healthy Haitian with dementia and psychosis. ${ }^{+}$

There is an urgent need to look out for, describe, and investigate the neurological aspects of infection with HIV. The average latent period of some types of HIV related neurological disease may be years. If so, neurological disease may be seen more often-even in patients who do not develop AIDS. The time consuming technique of psychometric testing may be necessary to pick up early and subtle changes, and such early recognition may prove vital so that, when it becomes available, antiviral treatment can be given. The number of people infected with HIV exceeds the number with AIDS by a factor of 50 to $100,{ }^{14}$ and these many people who are at risk of progressing to AIDS may also be at risk of developing HIV related neurological disease.

Christopher A CARNE Lecturer

MiCHAEL W ADLER Professor

Academic Department of Genitourinary Medicine,

Middlesex Hospital Medical School,

London W1 8AA

Correspondence to: Professor Adler.

1 Gajdusek DC, Amyx HL, Gibbs CJ, et al. Infection of chimpanzees by human T-lymphotropic retroviruses in brain and other tissues from AIDS patients. Lancet 1985; i:55-6.

2 Shaw GM, Harper ME, Hahn BH, et al. HTLV-III infection in brains of children and adults with AIDS encephalopathy. Science 1985;227:177-82.

3 Levy JA, Shimabukuro J, Hollander $\mathrm{H}$, et al. Isolation of AIDS-associated retroviruses from cerebrospinal fluid and brain of patients with neurological symptoms. Lancet 1985;ii:586-8.

4 Ho DD, Rota TR, Schooley RT. Isolation of HTLV-III from cerebrospinal fluid and neural tissues of patients with neurologic syndromes related to the acquired immunodeficiency
svndrome. $N$ Engl f Med 1985;313:1493-7.

5 Resnick L, di Marzo-Veronese F, Schupback J, et al. Intra-blood-brain-barrier sunthesis of HTLV-III specific IgG in patients with neurologic symptoms associated with AIDS or AIDSHTLV-III specific IgG in patients with neurologic
related complex. $N$ Engl f Med 1985;313:1498-504.

6 Goudsmit J, Wolters EC, Bakker M. Intrathecal synthesis of antibodies to HTLV-III in patients without AIDS or AIDS related complex. Br Med f 1986;292:1231-4.

7 Carne CA, Tedder RS, Smith A, et al. Acute encephalopathy coincident with seroconversion for anti-HTLV-HII. Lancet 1985; ii: 1206-8.

8 Piette AM, Tusseau F, Vignon D. Acute neuropathy coincident with seroconversion for anti LAV/HTLV III. Lancet 1986; i: 852 .

9 Snider WD, Simpson DM, Nielsen S. Neurological complications of acquired immune deficiency syndrome. Analysis of 50 patients. Ann Neurol 1983;14:403-18.

10 Price RW, Navia BA, Cho E-S. AIDS encephalopathy. Neurologic Clinics 1986;4:285-301.

11 Jordan BD, Navia BA, Petito C. Neurological syndromes complicating AIDS. Front Radiat Ther Oncol 1985;19:82-7.

12 Petito CK, Navia BA, Cho E-S, Jordan BD, George DC, Price RW. Vacuolar myelopathy pathologically resembling subacute combined degeneration in patients with the acquired pathologically resembling subacute combined degeneration
immunodeficiency syndrome. $N$ Engl I Med 1985;312:874-9.

13 Levy RM, Bredesen DE, Rosenblum ML. Neurological manifestations of the acquired immunodeficiency syndrome (AIDS): experience at UCSF and review of the literature. $f$ Neurosurg 1985;62:474-95.

14 Curran JW, Meade Morgan W, Hardy AM, et al. The epidemiology of AIDS: current status and future prospects. Science $1985 ; 229: 1352-7$

\section{Menière's syndrome: pathogenesis and treatment}

Menière's syndrome consists of a combination of vertigo, fluctuating hearing loss, and tinnitus, often associated with a sensation of pressure or fullness in the ears. Deafness and tinnitus increase during episodes of vertigo with improvement afterwards, but hearing progressively declines. The disease is most common between 30 and 60 and rarely starts in childhood or old age. ${ }^{1}$ Men and women are equally affected; three quarters of cases start unilaterally, but the numbers of bilateral cases gradually increase. ${ }^{12}$

The cause is endolymphatic hydrops - that is, an increase 